\title{
NASA INTEGRATED MODEL-CENTRIC ARCHITECTURE (NIMA) MODEL USE AND RE-USE
}

Mike Conroy \& Rebecca Mazzone, Kennedy Space Center

Wei Lin, Ames Research Center

\begin{abstract}
This whitepaper accepts the goals, needs and objectives of NASA's Integrated Model-centric Architecture (NIMA); adds experience and expertise from the Constellation program as well as NASA's architecture development efforts; and provides suggested concepts, practices and norms that nurture and enable model use and re-use across programs, projects and other complex endeavors. Key components include the ability to effectively move relevant information through a large community, process patterns that support model reuse and the identification of the necessary meta-information (ex. history, credibility, and provenance) to safely use and re-use that information.
\end{abstract}

\section{ACKNOWLEDGEMENTS}

The authors brought decades of modeling and simulation experience to this development effort. They hold or held leadership roles in previous NASA design environment initiatives, Constellation's (CxP) system engineering and integration organization, ground operations simulation, Orion modeling and simulation, NASA's system architecture and tool development initiatives, and various engineering and development activities spanning the complete system lifecycle. They also called heavily upon their relationships across NASA, in industry and in academia to better explore the past as well as plan for the future. Special thanks are in order for Jamie Adams and Linda Bromley of the Johnson Space Center for guidance and encouragement throughout the process, and to Martin Steele and Gary Mosier for sharing their expertise and helping to map the necessary model-based processes to both NASA Standard 7009 and the associated guide book. 


\section{NIMA OBJECTIVES}

NASA believes that the ability to make more informed and timely decisions is a key enabler for reducing cost and improving schedule, product and workforce performance. NASA also believes that the first step toward more informed and timely decision making is a move from a document-centric design approach to a model-centric design architecture across the Agency.

NASA has 4 model-centric architecture goals:

Goal 1 Increase system affordability through use of a model-centric architecture

Goal 2 Achieve interoperability within and among programs, projects, centers and external partners through use of a model-centric architecture

Goal 3 Inform/train invigorate workforce on model-centric architecture

Goal 4 Improve product quality and success through use of a model-centric architecture

The NASA Integrated Model-Centric Architecture (NIMA) initiative is charged with achieving these goals. NIMA spans four technical communities of practice: Model-Based Systems Engineering (MBSE), Modeling \& Simulation (M\&S), Computer Aided Design (CAD), and Product Data \& Lifecycle Management (PDLM).

NIMA will attempt to formalize and infuse a model-based design and development architecture throughout the NASA engineering community by incorporating successful tools and practices from industry, NASA centers and other government organizations into the NASA engineering culture. A key practice is the application, and informed reapplication, of models and simulations to meet the design and development needs of the complex lifecycles associated with advanced space systems. Other components include representation frameworks, executive guidance, NASA Standard 7009, tools, supporting infrastructure, other standards, processes, training, Product Data Management (PDM), Product Lifecycle Management (PLM), partnerships, and human capital management.

This document specifically focuses on application and reapplication of models and simulations throughout the system development lifecycle. It calls upon success in industry, academia, the space community and Defense, as well as past NASA success in complex programs and the existing NASA system engineering lifecycle. It is focused on providing an overall use and reuse philosophy, associated meta-methods, information access and linkage to increasingly detailed information as it emerges. Specific attention is paid to NASA Standard 7009 elements that enable and empower informed reuse, as well as variations in reuse methodologies associated with the different lifecycle phases (concept development to utilization to disposal).

\section{Model USE AND Re-USE GoALS}

The NIMA Use and Re-Use (URU) Team is comprised of practitioners in the fields of engineering, software development, modeling, simulation, systems engineering and management. Their goals were to:

1. Identify and classify goals, needs and objectives associated with model and simulation use and subsequent re-use, broken out by product lifecycle phase and leadership role, to both frame discussion and models

10 Deep Thoughts About Software enable recommendations that will meet global needs as well as local. 
2. Capture modeling and simulation processes and practices from industry, academia, professional societies and other government agencies in order to provide a better understanding of efforts to date and enable maximum reapplication of good ideas.

3. Publish the results, by leadership role and life cycle phase, to identify gaps for future research and development, to document our accomplishments and better plan for the next accomplishments.

As Engineers, Designers, Managers, Inventors, Technologists and Humans we use models and simulations to understand systems and support our decisions. We model things, be they systems or processes or items, to better understand what they are. During this process, we build the model to the detail necessary to meet our needs. Once we have a model that seems to represent what we want to study, with sufficient detail for the study, we simulate how the model, and usually several other models, behave together. This simulation should be performed with a level of rigor that is commensurate with the criticality of the study. Through this process we are able to gain and preserve insight, increase understanding, and subsequently make better decisions. It is hoped that when we make these decisions we fully understand the level of detail and fidelity, or lack thereof, applied to creating the information (models and simulations) upon which our decisions are based. The level of detail, fidelity and processes used combine to represent the overall credibility of the results. NASA Standard 7009 helps formalize the representation of this credibility so it may be incorporated into future decisions.

Complex endeavors are often undertaken by large teams with varied relationships. Any study of model use and reuse, as applied to large teams performing complex activities, would be incomplete at best if it did not address the roles played by the various team members, the rules associated with those roles and how those roles change as the endeavor matures. To this end, we have identified 5 major roles associated with large complex activities. These roles are introduced in the table below:

\begin{tabular}{|l|l|}
\hline Role: & Associated With: \\
\hline Executive & $\begin{array}{l}\text { Mission and policy development, partnerships, resources, plans, overall goals of } \\
\text { the endeavor }\end{array}$ \\
\hline $\begin{array}{l}\text { Architecture } \\
\text { Development }\end{array}$ & $\begin{array}{l}\text { Concept development and maturation, operations concepts, initial milestones, } \\
\text { needs, parametric analysis and cost estimation for the identified alternatives }\end{array}$ \\
\hline Program Development & $\begin{array}{l}\text { Concept of operations, systems model, interfaces, system of systems analysis, } \\
\text { program and project milestones, programmatic objectives, cost and schedule } \\
\text { performance, overall system integration }\end{array}$ \\
\hline Project Development & $\begin{array}{l}\text { System engineering, systems engineering, concepts of operations, interfaces, } \\
\text { cost and schedule performance, requirements }\end{array}$ \\
\hline Engineering & $\begin{array}{l}\text { Detailed system designs, system performance, cost performance, schedule } \\
\text { performance, system integration activities, deliveries, alternatives, logistics, } \\
\text { manufacturing }\end{array}$ \\
\hline
\end{tabular}

TABLE 1: ROLES FOR COMPLEX ACTIVITIES 
If we take the above roles and map them across lifecycle phases (Pre-A to F), we can represent their participation in the various phases (concept through operations and disposal) as well as their viewpoint $(100,000$ foot level down to 1 foot level), presence in the product teams, and their overall representation in the larger team. This mapping is shown in Figure 1. The relevant NASA gateway reviews are included at the bottom and include: the Mission Concept Review (MCR), the System Requirements Review (SRR), the Preliminary Design Review (PDR), the Critical Design Review (CDR) and the Operational / Flight Readiness Review (O/FRR).

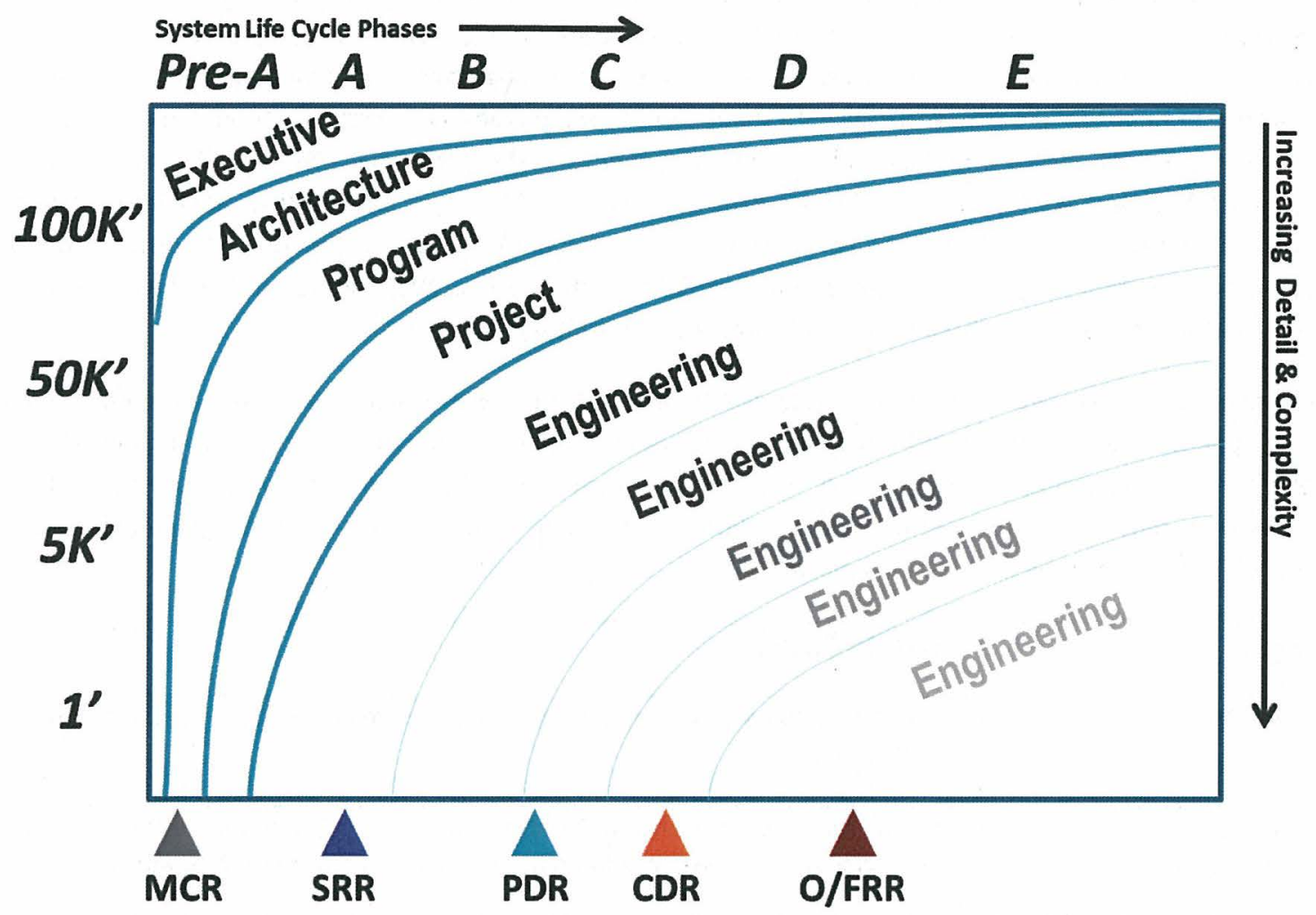

FIGURE 1: ROLE TO LIFECYCLE PHASE MAPPING

Not readily apparent above is the fact that, as we go down the list of Roles and as the product or program matures across time, the number of people and complexity associated with the activity increase significantly. This creates a situation where those in the architecture role that comprised the majority of the team at inception become a smaller and smaller percentage of the workforce as the project matures.

Successful endeavors seem to have some common behaviors associated with and around these Roles. The rules fall into two general areas: Communication and Scope.

- Communication:

- The Role above you - the Parent, the customer - provides dollars, goals and measures of your success. You need to talk to them in their language, honoring their norms, or they will find someone who will. 
- The Roles below you - the Children, the suppliers - provide that which you need to satisfy your customer and enable your success. They need to learn your language.

- This is called the chain of command. However, it must be recognized that miscommunication across these interfaces can limit or destroy progress, with the onus on each Parent to ensure overall program and project success.

- Scope:

- Each Role has a set of norms that govern local behavior. These include: motivation, reward structure, punishment structure, organizational physics and culture.

- Norms will vary from role to role, project to project, customer to customer, sometimes week to week. It is advisable not to look across too many Roles and expect your norms to still apply. One can look closely at another's role, but to be effective, one must observe as if a part of the remote system.

In addition, in order to add value beyond the local group, what is learned must be appropriately shared. "Appropriately Shared" is not the same as "Publish Everything". It is a value adding process that assumes the Parents defined what is needed as well as the format in which it is required, assumes that there is sufficient local knowledge to identify what meets those standards and requires a place for information that supports appropriate sharing. For this discussion, the terms Compose and Decompose require some clarification.

- Compose: Accept models, data, simulations, designs and knowledge from Child projects or systems; provide an integrated view, including all of the necessary credibility information to support subsequent reuse or reapplication; then publish the results for use by the Parent project or systems in their analysis and to better inform the Child projects of how their efforts integrate into the greater whole.

- Decompose: Accept models, data, simulations, requirements and knowledge from Parent project or system; format or organize as necessary and share with Child projects or systems, providing the necessary credibility information for subsequent use; then publish for use by the Children in their design and development work and by the Parent to both better understand the products being developed and ensure the teams are on the right path.

The minimum needs for sharing are met when we can compose information for effective use by the Parent side of the effort, can appropriately decompose information for effective use by the Child side of the effort, and can deliver the information in a reliable manner.

As time progresses and programs mature, the models and information exchanged will change as well. The table below describes this progression. 


\begin{tabular}{|c|c|c|}
\hline Role: & Starts With: & Moves To: \\
\hline Executive & $\begin{array}{l}\text { Early Artwork, Sketches, Goals, Directives } \\
\text { (pictures, simple spreadsheets) }\end{array}$ & $\begin{array}{l}\text { Parametric Data, System Models, Simulation } \\
\text { Products, Decisions } \\
\text { (system simulations, cost / performance } \\
\text { models) }\end{array}$ \\
\hline Architecture & $\begin{array}{l}\text { Early Concepts, System Segment } \\
\text { Simulations, Parametric Data } \\
\text { (pictures, animations, spreadsheets) }\end{array}$ & $\begin{array}{l}\text { Architecture Models, System Simulations } \\
\text { (SysML, lifecycle simulations, cost / } \\
\text { performance analysis) }\end{array}$ \\
\hline Program & $\begin{array}{l}\text { Early System Models, Program Simulations, } \\
\text { Scenarios } \\
\text { (spreadsheets, databases, animations) }\end{array}$ & $\begin{array}{l}\text { Program Models, Program Simulations, Cost } \\
\text { and Performance Simulations } \\
\text { (SysML, simulations, program models, } \\
\text { discrete event simulations) }\end{array}$ \\
\hline Project & $\begin{array}{l}\text { Early Concepts, System Simulations, } \\
\text { Parametric Analysis } \\
\text { (databases, SysML reference models) }\end{array}$ & $\begin{array}{l}\text { System Models / Simulations, Process } \\
\text { Simulations, Design Visualization } \\
\text { (detailed SysML, PM software, DES, Cradle, } \\
\text { DOORS, Catia) }\end{array}$ \\
\hline Engineering & $\begin{array}{l}\text { Early Concepts, Sub-System Simulations, } \\
\text { Parametric Data, SysML Needs } \\
\text { (concept sketches, requirements, goals, } \\
\text { videos) }\end{array}$ & $\begin{array}{l}\text { CAD/CAE, PDM/PLM, System Visualization } \\
\text { and Simulation, Visualization } \\
\text { (Pro-E, Windchill, Catia, Unigraphics, DOORS, } \\
\text { Cradle, FEA, ..) }\end{array}$ \\
\hline
\end{tabular}

TABLE 2: EVOLUTION OF INFORMATION PRODUCTS

\section{Model USE AND Re-USE ConCEPTS}

\section{DEFINITIONS}

The definitions below apply to this document. They are based upon other documents, studies done over the past decade, use across the Constellation Program (CXP), use across other NASA projects, discussions across the NIMA teams and dictionary references.

MODEL

A model is static, like a noun. It is a representation of a thing, such as a device, a behavior, a phenomenon, a process or a system. A model is studied to learn about and better understand the thing that it represents. Models may also contain a temporal element and could then represent the item being studied over a period of time. 


\section{SIMULATION}

A simulation is dynamic, like a verb. It is the active representation of a process or activity that has occurred, is occurring or is expected to occur. In a simulation we expect things to move and change in response to stimulus and the passage of time. A simulation is studied to learn about and better understand the activity. A simulation is expected to produce results that can be stored and passed to other simulations. As these stored forms are no longer dynamic, and do not respond to stimuli, they now take on the attributes of a model for use in inspecting and understanding the simulation they represent.

\section{DECISION}

A decision is something that requires information, knowledge and experience. The information comes, in part, from models and simulations. The decision should reference the models and simulations supporting the decision. And, those models and simulations must have been performed with rigor commensurate to the decision they support. NASA Standard 7009 provides our framework for representing and communicating the rigor associated with development of the decision support products.

This guide is intended to help engineers, managers, leaders, customers and suppliers, at any phase of their system life cycle, better understand both the principles associated with NASA's model-centric design and how those principles contribute to better, more sustainable products with lower life cycle costs. 


\section{Model USE ANd Re-USE Benefits}

\section{SCIENTISTS AND ENGINEERS}

NIMA provides a foundation that will allow for more informed requirements and support more informed design. Model use and model reuse are key elements to rapid and effective design and development, no matter the life cycle phase. This guide defines both the incoming and outgoing model expectations to ensure that teams get the model-based information (ex. needs, requirements, specifications, past work) they need to perform their job as well as provide the model-based products that allow others to successfully complete theirs.

\section{PROJECt MANAgERS}

NIMA provides core and common design practices and data structures that enable project and data integration. This guide provides an overview of what is needed to produce and utilize reusable model-centric data as well as what a project manager should expect in terms of reusable data throughout the lifecycle.

\section{CUSTOMERS}

NIMA formalizes and empowers relationships across the project lifecycle. This document provides customers with relationship expectations regarding model-centric design and outlines for them the expected benefits associated with the process. In a model-centric world the customer deals much more with use cases and simulations as opposed to requirements and verification steps. This makes it much easier to understand what is being built, as well as inspect the interim products during the development process.

\section{SUPPLIERS AND MANUFACTURERS}

NIMA opens the design process to those who will actually produce the final products (i.e., Commercial Providers, Manufacturers, Universities, Other Government Agencies and/or Other NASA Centers). Representation of the systems and the expected performance, early in the lifecycle, in a portable format, enables inclusion of the supply and manufacturing community into the design process. The same way that including an operator in the design process led to more operable systems, this will allow suppliers a better understanding of what is intended and enable them to help guide the design process towards more producible systems.

\section{Program Managers}

NIMA provides the program manager with a model-centric framework to help create and operate NASA's complex next generation exploration systems. This document provides the program manager with an understanding of what is possible in the way of model-centric design as well as what they should look for and expect as their systems (and systems of systems) move through the various lifecycle phases associated with multi-decadal endeavors.

\section{OPERATIONS}

NIMA provides operations with rich information on the intended systems throughout its life cycle, as well as a seat at the design table. This information, available early in the lifecycle, also allows the operational community to make more informed decisions concerning the incorporation of new capabilities into their operational systems and processes. 


\section{RECOMMENDATIONS}

\section{Provide a Standard WORKPLACE THAT ENABLES MOdEL USE AND RE-USE}

A look at work processes, project design, Constellation Best Practices, Constellation Lessons Learned, past PDM/PLM efforts and successful projects indicate two basic workplace needs for teams that support large endeavors. Teams need an internal place to work and an external place to share, or publish, what they are working on.

- The internal space will contain alternatives, works-in-progress, options, failed efforts and items in the review process. Much of this data is not intended for wider consumption but is essential for the effective operation of the team. Internal data will be under less formal configuration control and will be more often aligned with the internal team structure than the overall project structure.

- The external space is for publishing information to be used across the Program, Project or Partners. Information will be organized along strict Program lines and will be under strict configuration control.

These places are necessary from the executive leadership level on down to the smallest task team and must be provided across Programs and Projects as standard services. Failure to do so will increase standup efforts, fragment processes (this team does this that way), require team specific training and ensure duplication of work. Providing these capabilities at Standup will allow for common training, common processes, easier re-use of work, and will let teams focus on adding value as opposed to continually re-creating and re-organizing the file shares used for storing and sharing data in hope of finding what they need.

\section{Provide a Formulation / Standup Template that encourages Re-Use of Models}

\section{AND SIMULATIONS:}

NIMA, with its focus on MBSE, SysML, Modeling, Simulation and Structured/Architected Data, provides NASA an unprecedented foundation upon which to conceive, build and manage new systems. As with any powerful tool; guidelines, instructions and processes are critical to safe and successful application. Again, research and observation have shown that structural and process sub-optimizations during the Program or Project Standup phase are exceedingly difficult and costly to correct later in the lifecycle. A Template for Program or Project Standup that provides the basic structure necessary for NIMA-enabled success must be provided to take advantage of the benefits of planned, organized and available model-centric data.

\section{Provide a Leadership Process that Re-Uses Models and Simulations}

With a place to appropriately store and share models and simulations for both use and re-use, and a structure that organizes these places across a Program or Project, what remains is the need for a formal process for moving models, simulations and knowledge up, down and across the Program(s). Teams in a Program or large project exist in natural hierarchy with needs coming from near the top and products coming from near the bottom. As the Program or Project matures, any one Team, no matter the place in the hierarchy, will perform at least 2 major functions: 
- They will receive data or products from subordinates, add value to that data or product, and provide it to their superior.

- They will receive needs from their superior, expand upon those needs as necessary, and provide the needs, as well as the additional data, to subordinates.

Both of these functions are governed by NASA Program and Project management processes. However, to take full advantage of the opportunities provided by MBSE in general - and NIMA's pattern of model use and re-use in particular - a standard tailoring of these management processes is highly recommended. This tailoring would recommend where and how to store and share models, provide guidelines to help establish the necessary organizational structure to enable this sharing, and lay out the basic structural processes to use and re-use models, simulations and knowledge across the endeavor.

\section{Provide a NASA Std. 7009 Based Reference to Help Guide Appropriate Use and Re-}

\section{USE:}

The credibility of M\&S results should be assessed using, at a minimum, the Credibility Assessment Scores (CAS) and the processes detailed in NASA Standard 7009. This assessment process involves evaluating the M\&S results in eight areas: Verification, Validation, Input Pedigree, Results Uncertainty, Results Robustness, Use History, M\&S Management, and People Qualifications. NASA is providing a NASA Standard 7009 Handbook as well as NIMAspecific training and worksheets to assist in the development of credibility assessments. Additional data on credibility assessment and recommended CAS data for various lifecycle phases are included as an appendix to this white paper. 


\section{CONCLUSIONS}

In order to successfully Use and Re-Use Models and Simulations we must define and meet key organizational and structural needs:

1. We must understand and acknowledge all the roles and players involved from the initial need identification through to the final product, as well as how they change across the lifecycle.

2. We must create the necessary structural elements to store and share NIMA-enabled information throughout the Program or Project lifecycle.

3. We must create the necessary organizational processes to stand up and execute a NIMA-enabled Program or Project throughout its lifecycle.

NASA must meet all three of these needs to successfully use and re-use models. The ability to Reuse Models a key component of NIMA and the capabilities inherent in NIMA are key to accomplishing NASA's space exploration goals. 


\section{Appendix A: Notional LIFECyCLE CREDibiLity ReCOMmendations}

The CAS recommendations in this appendix build upon Role and Lifecycle discussions in the Model Use and Re-Use white paper and incorporate information from the NASA Systems Engineering Handbook on gateway reviews (SRR, CDR, PDR...) as well as information and lessons from the Constellation program. They are organized along the lines of the planned gateway reviews and associated initial credibility levels from the Constellation Program. It should be noted that Constellation was terminated prior to formalizing these recommendations and that the actual levels applied would have been under the purview of the Program or Project Systems Engineer and Technical Authority. It should also be noted that Constellation was a multi-billion dollar multi-decadal program. These levels are likely not appropriate for smaller projects. However, that decision also falls under the purview of the associated program or projects systems engineer and technical authority.

The figure below identifies the eight areas evaluated while performing a credibility assessment. Each area is ranked from 0 to 4 , with 0 representing low credibility in an evaluation area and 4 representing high credibility. The criteria for meeting each level are also provided.

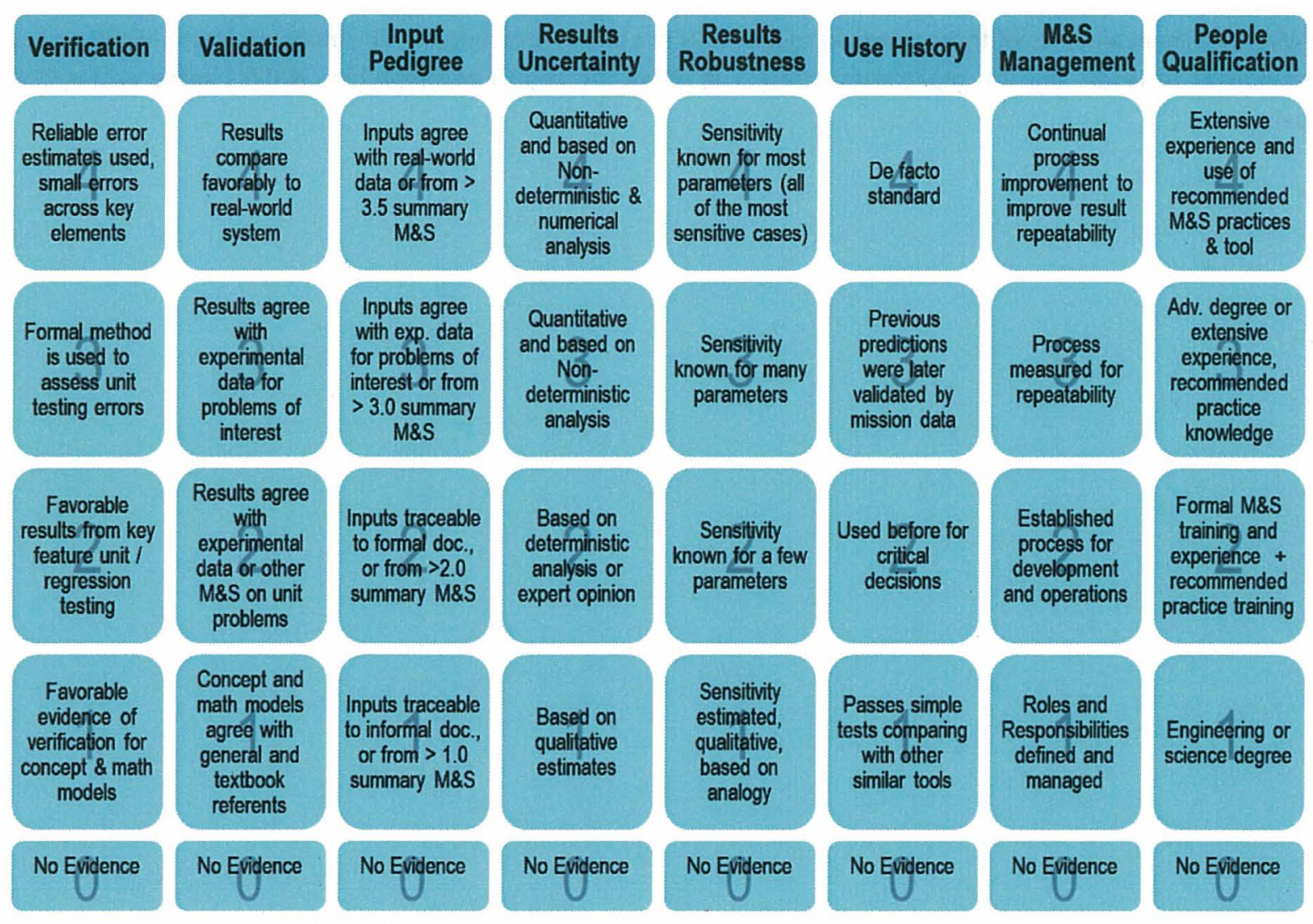

FIGURE 2: CREDIBILITY ASSESSMENT CRITERIA 


\section{Credibility Recommendation for Peer Review / Concept Development}

Credibility scores during Peer Review, and Concept or Technology Development are expected to be fairly low (1's and 0 's) as these activities consist primarily of loosely structured examinations of new ideas, usually without central control and mostly oriented toward small studies. An example of minimum suggested credibility scores for Peer Review / Concept Development (notionally Pre Phase A) is included below. This CAS indicates that the work was performed by members of the technical team and the results were in line with what was expected. The major benefits of the CAS at this point in the lifecycle are to record: the fact that some basic verification was done, that technical members of the team performed the analysis and that the center items were not addressed. While it is possible that additional rigor could be applied and recorded in the concept phase, it was not necessary. This profile also serves as a flag to subsequent users of the results that this analysis is likely not appropriate for re-use outside of the concept development phase, while preserving the knowledge that some work was done that could be called upon if necessary.

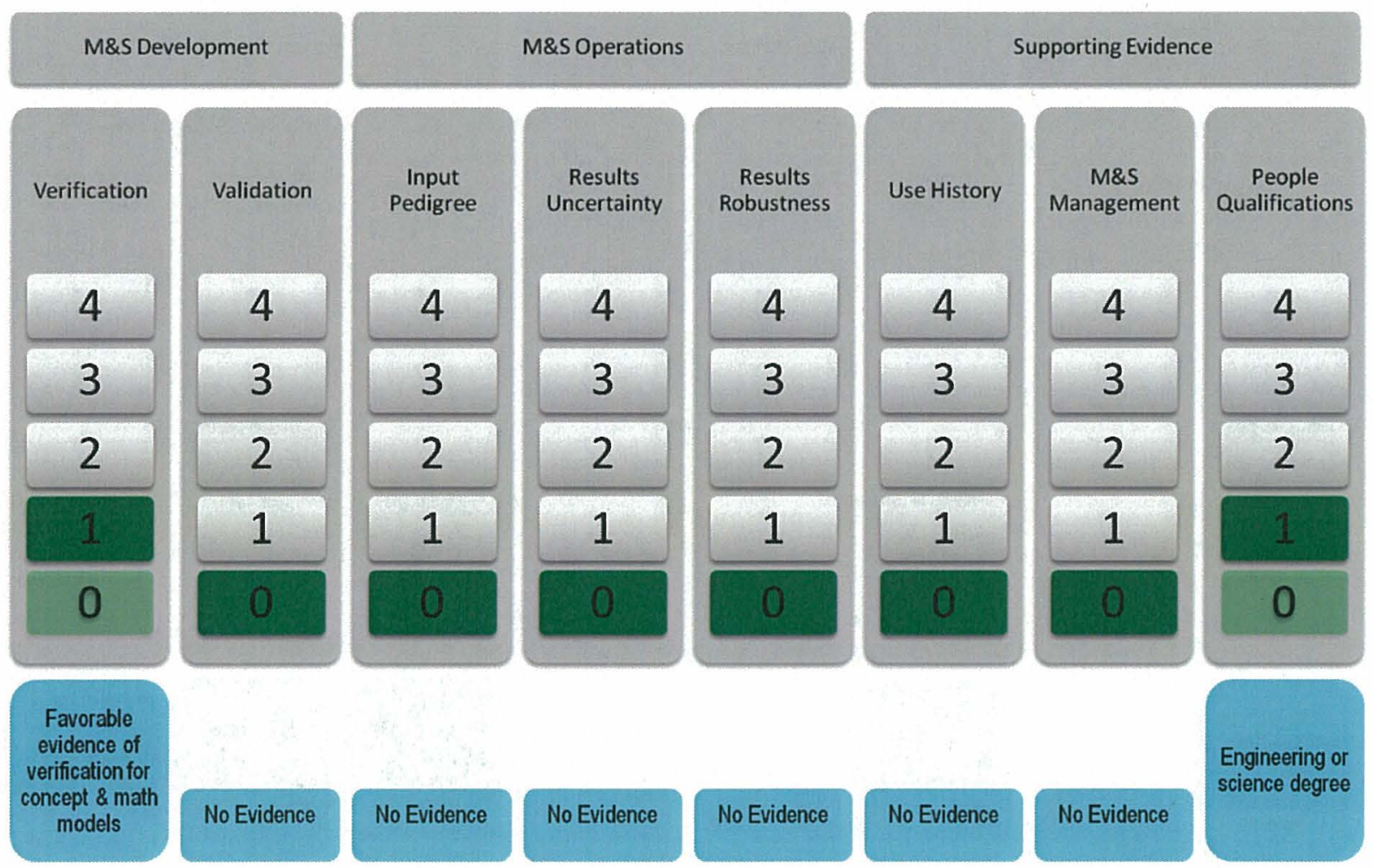

FIGURE 3: EXAMPLE PEER REVIEW-TYPE CREDIBILITY ASSESSMENT 


\section{CRedibility Recommendation for System ReQuiREMents ReVIEW (SRR)}

SRR CAS scores should demonstrate maturation of both the work and the processes to ensure that the system requirements are appropriate. Progression is expected in the areas of Verification, Input Pedigree, Use History and M\&S Management, as outlined below by the darker colored boxes. The major benefits of the CAS at this point in the lifecycle are related to ensuring that the foundational analyses that went into the requirements development process are understood as well as repeatable. The sample CAS below indicates that while the work was performed by a technical team similar to that which performed the concept studies, additional work has been done to ensure the correctness of the results and implement processes to ensure that the right work was performed and the work can be repeated. While it is possible that additional rigor could be applied and recorded, the suggested scores should be adequate for the System Requirements phase. Also, this profile is a flag to subsequent users of the results that this analysis is not appropriate for re-use outside of requirements development, while preserving the knowledge that some work was done that could be called upon if necessary.

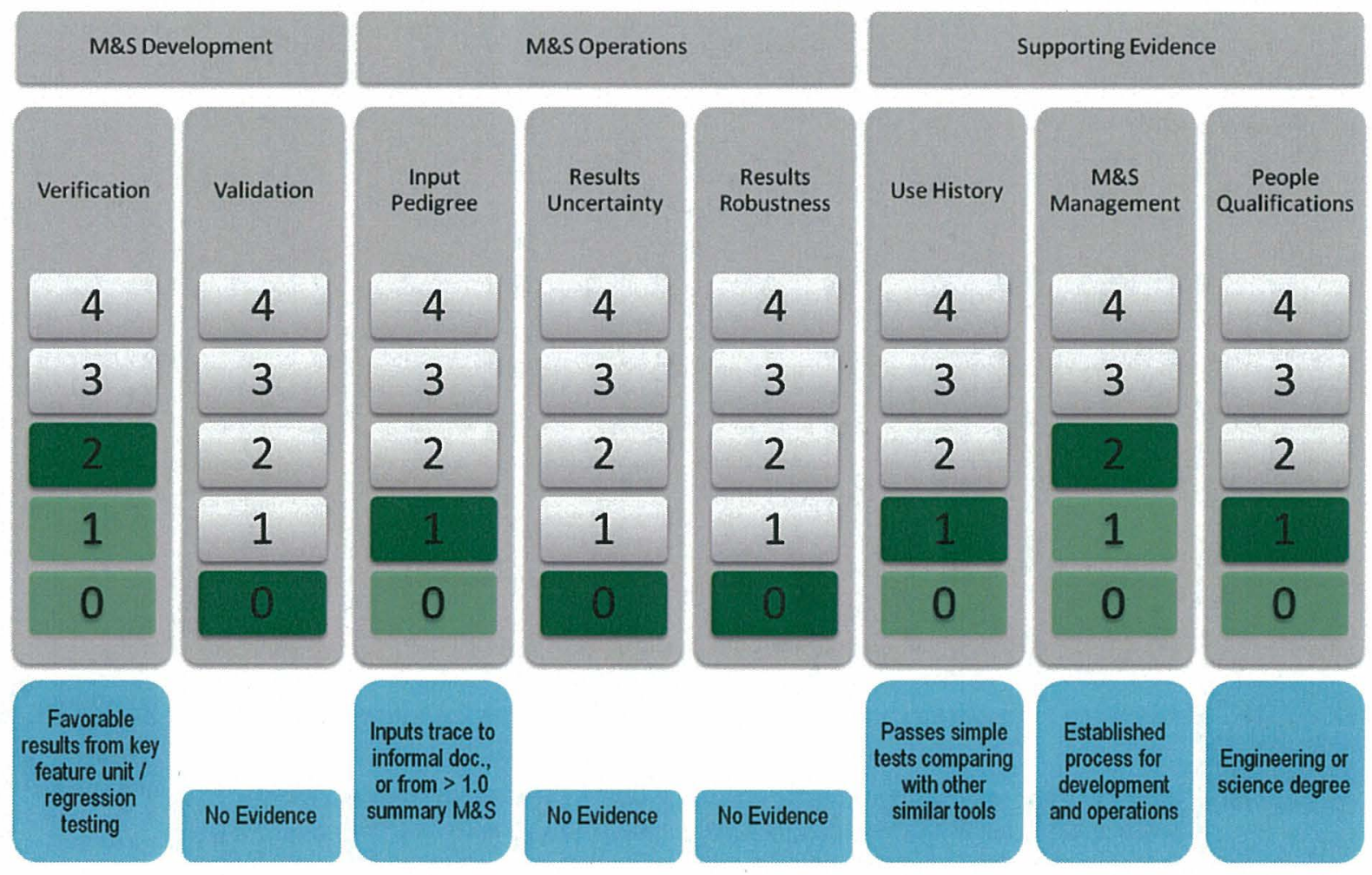

FIGURE 4: EXAMPLE SRR-TYPE CREDIBILITY ASSESSMENT 


\section{Credibility Recommendation for Preliminary Design Review (PDR)}

PDR CAS scores should demonstrate maturation of both the work and the processes to ensure that the preliminary system designs are appropriate. Progression is expected in the areas of Validation, Input Pedigree, Uncertainty and Use History over the work that supported the System Requirements Review. This is outlined below by the darker colored boxes. The major benefits of the CAS at this point in the lifecycle are related to ensuring that the analysis that went into the preliminary designs is well understood, appropriate and repeatable. This CAS indicates that while the work was still performed by a technical team similar to that which performed the Requirement Review studies, additional work has been done to ensure and test the correctness of the results as well as implement processes to ensure that the right work was performed and that it could be repeated. While it is possible that additional rigor could be applied and recorded, the suggested scores should be adequate for the Preliminary Design Review. Also, this profile is a flag to subsequent users of the results that this analysis is not appropriate for re-use outside of Preliminary Design Review environment, while preserving the knowledge that some work was done that could be called upon if necessary.

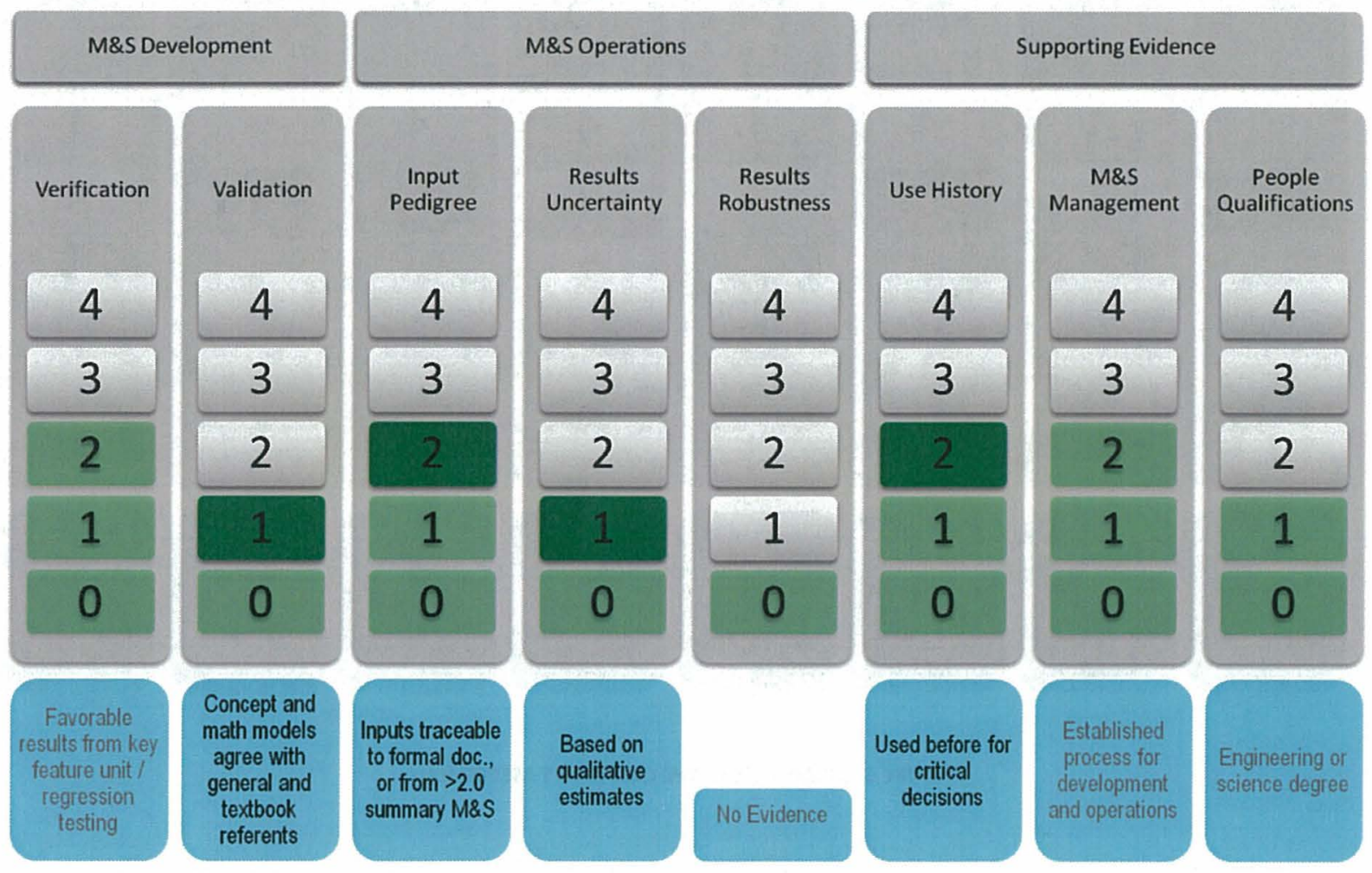

FIGURE 5: EXAMPLE PDR-TYPE CREDIBILITY ASSESSMENT 


\section{CRedibility Recommendation for CRItical Design ReView (CDR)}

CDR CAS scores should demonstrate maturation across all eight Credibility areas as outlined below and identified by the darker colored boxes. These CAS scores allow appropriate model use and reuse across the CDR process including system level testing. The major benefits of the CAS at this point in the lifecycle are related to ensuring that the analysis is well understood, appropriate and repeatable. While additional rigor could be applied, the suggested scores should be adequate to flag for subsequent users that this analysis is not appropriate for re-use outside of Critical Design Review environment, while preserving the knowledge that some work was done that could be called upon if necessary.

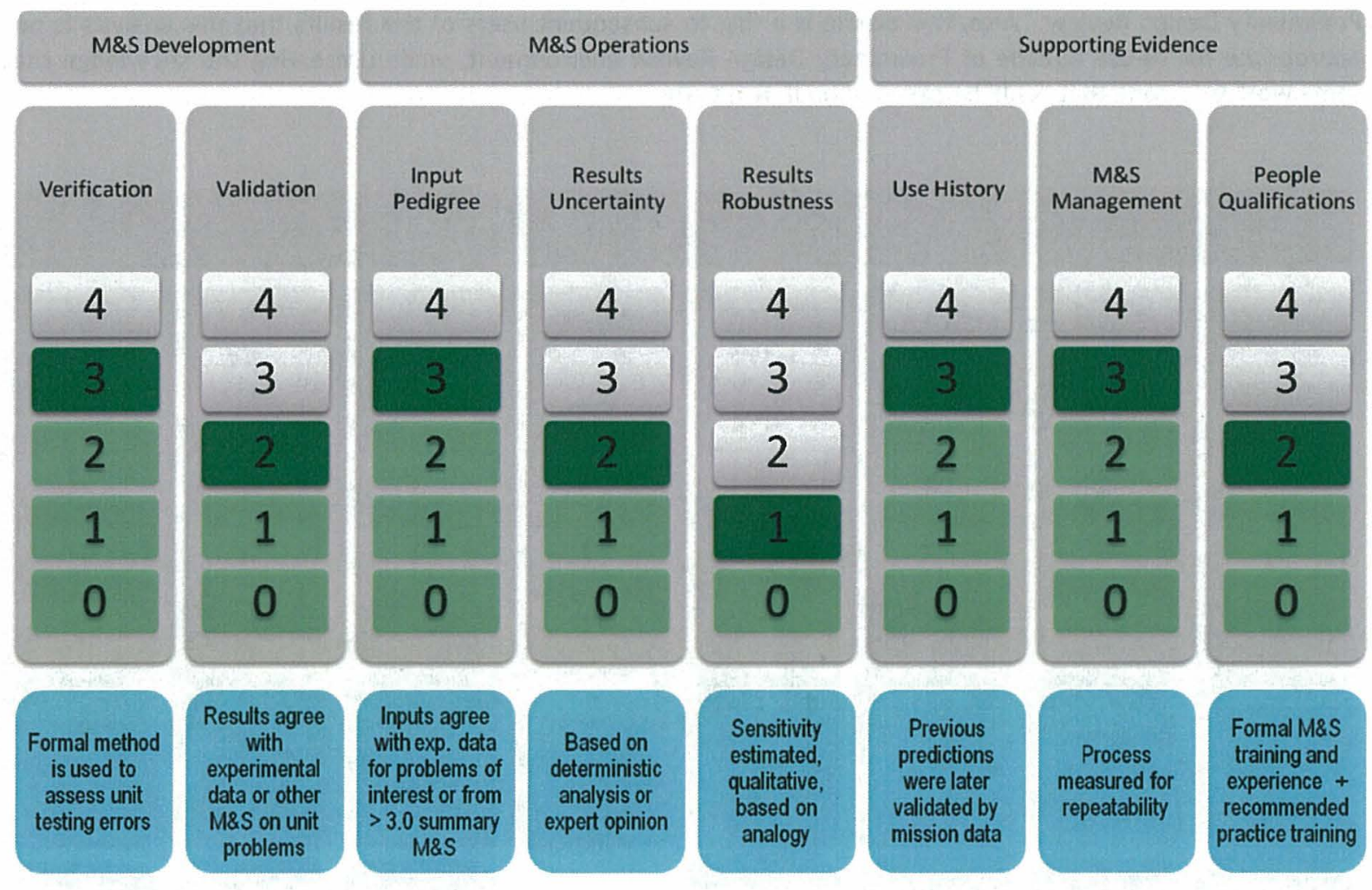

FIGURE 6: EXAMPLE CDR-TYPE CREDIBILITY ASSESSMENT 


\section{Credibility Recommendation for Operational Readiness Review / Flight Readiness REVIEW (ORR/FRR)}

CDR CAS scores should demonstrate maturation across seven of the eight Credibility areas as outlined below. These CAS scores allow appropriate model use and re-use across the ORR/FRR process, including system level testing. The major benefits of the CAS at this point in the lifecycle are related to ensuring that the analysis is well understood, appropriate and repeatable. While additional rigor could be applied, the suggested scores should be adequate to support decisions for Operational or Flight use. It should be noted that even at this phase of the program lifecycle, the scores are not "All $4 \mathrm{~s}$ ", and a goal of "All $4 \mathrm{~s}$ " is likely not appropriate unless deemed so by the Program or Project System Engineering and Technical Authorities.
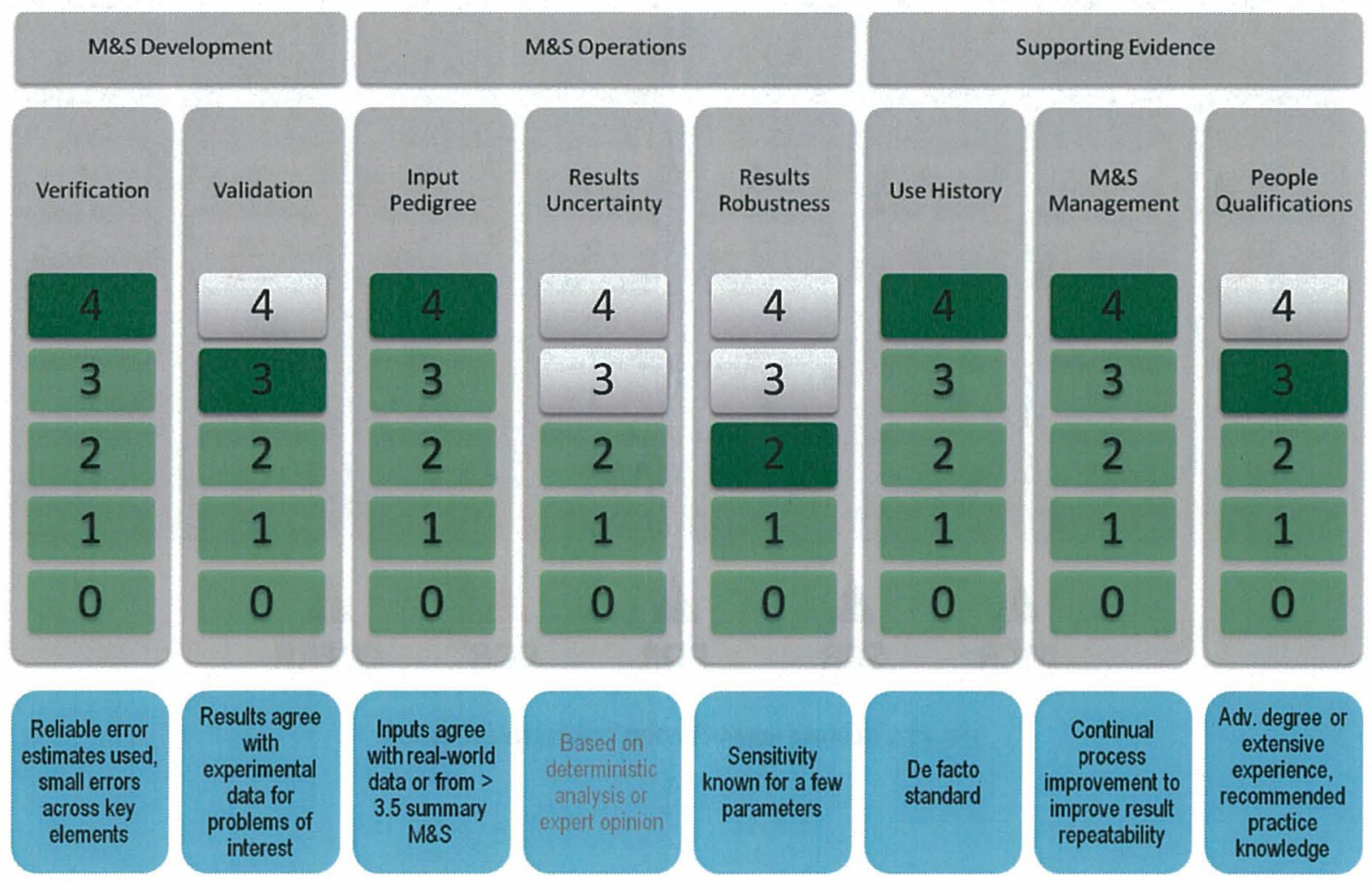

Continual

process

improvement to

improve result

repeatability

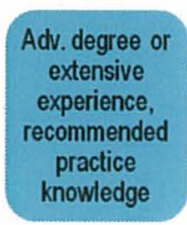

FIGURE 7: EXAMPLE ORR/FRR-TYPE CREDIBILITY ASSESSMENT 


\section{Recommended Credibility Score Roll Up, All On One Chart}

The Credibility Assessment Score is expected to increase as a Program or Project matures. The tables above provide notional scores for a large manned space flight program (CXP) at various program gateway reviews. The table below rolls those recommended gateway review scores up into a single format to both show the credibility maturation and enable a discussion of credibility for smaller projects or programs.

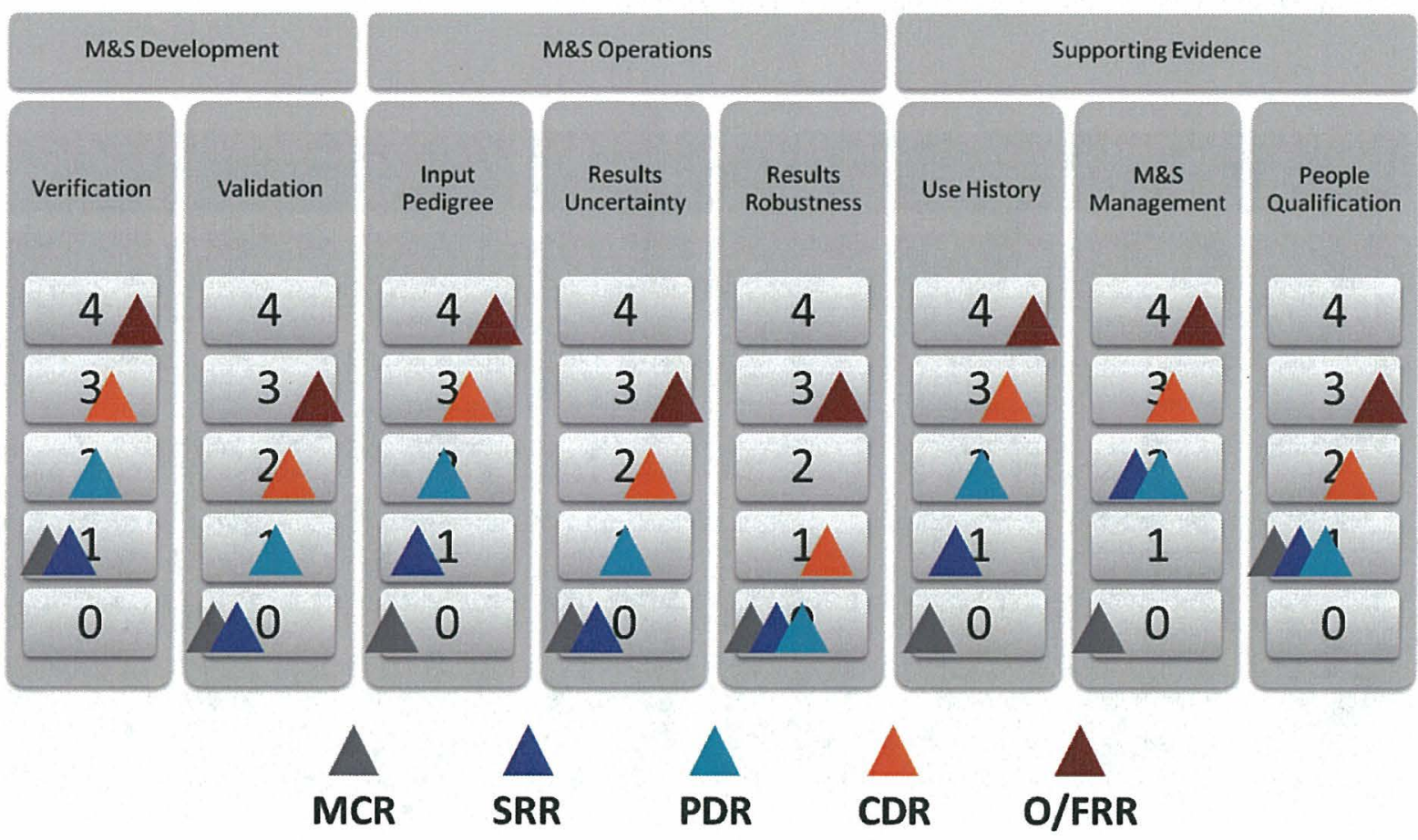

FIGURE 8: EXAMPLE HUMAN SYSTEM CREDIBILITY EVOLUTION 


\section{Alternative Credibility Score Roll Up \\ Class D Project Recommended Credibility Scores}

An example of an alternative to the above human rated system CAS profiles, the one below has been provided by the Goddard Space Flight Center as appropriate for Class D missions. These missions are of low cost and short duration and as such the program or project may tolerate risk in excess of that which is acceptable for higher classification missions. Not only is the operational phase of the mission short, so are the formulation and implementation phases. With small budgets come limited manpower, little time for "deep" analysis and software testing, a streamlined Integration \& Test phase, and a small likelihood of either test beds or engineering models being developed to support M\&S validation prior to development of the flight hardware. Given the above, the following Credibility Scores are representative of expectations for a notional Class D mission.

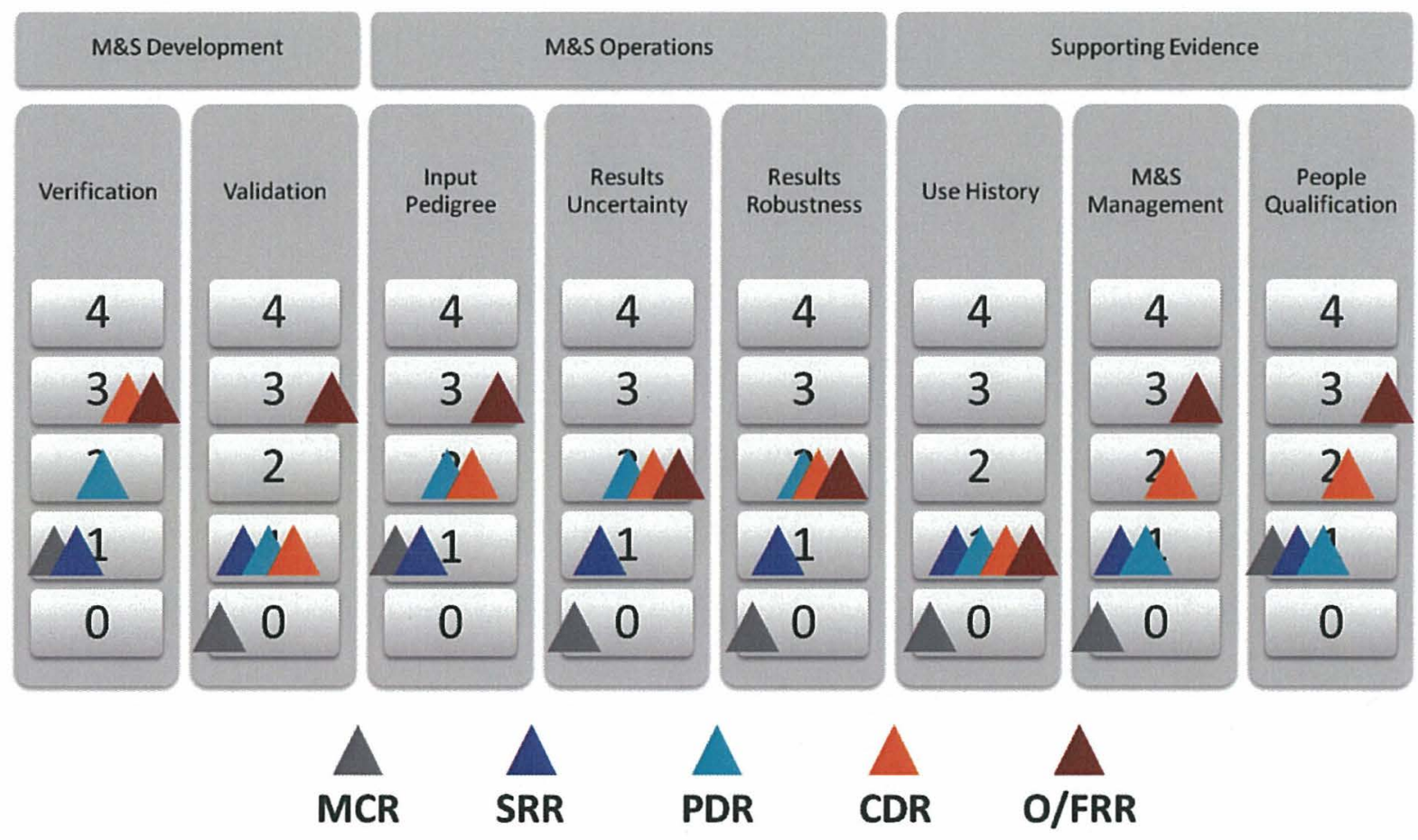

FIGURE 9: EXAMPLE CLASS D MISSION CREDIBILITY EVOLUTION 